\title{
Article \\ Antiviral Activity of Two Marine Carotenoids against SARS-CoV-2 Virus Entry In Silico and In Vitro
}

\author{
Sung-Kun Yim ${ }^{1, *}$, Inhee Kim ${ }^{2}$, Boyd Warren ${ }^{1}$, Jungwon Kim ${ }^{2}$, Kyoojin Jung ${ }^{1}$ and Bosung $\mathrm{Ku}^{2}$ \\ 1 Marine Biotechnology Research Center, Jeonnam Bioindustry Foundation, 21-7, Nonggongdanji 4Gil, \\ Wando-eup, Wando-gun 59108, Jeollanam-do, Korea; boydtwarren@gmail.com (B.W.); kjjung@jbf.kr (K.J.) \\ 2 Medical \& Bio Decision (MBD) Co. Ltd., \#B-8F, 145 Gwanggyo-ro, Yeongtong-gu, \\ Suwon-si 16229, Gyeonggi-do, Korea; ihkim@mbdbiotech.com (I.K.); \\ jungwonk@mbdbiotech.com (J.K.); goos4684@mbdbiotech.com (B.K.) \\ * Correspondence: skyim01@jbf.kr; Tel.: +82-10-4016-6745; Fax: +82-61-555-1797
}

Citation: Yim, S.-K.; Kim, I.; Warren, B.; Kim, J.; Jung, K.; Ku, B. Antiviral Activity of Two Marine Carotenoids against SARS-CoV-2 Virus Entry in Silico and in Vitro. Int. J. Mol. Sci. 2021, 22, 6481. https://doi.org/ $10.3390 /$ ijms 22126481

\section{Academic Editor:}

Sugunadevi Sakkiah

Received: 28 April 2021

Accepted: 15 June 2021

Published: 17 June 2021

Publisher's Note: MDPI stays neutral with regard to jurisdictional claims in published maps and institutional affiliations.

Copyright: (c) 2021 by the authors. Licensee MDPI, Basel, Switzerland. This article is an open access article distributed under the terms and conditions of the Creative Commons Attribution (CC BY) license (https:// creativecommons.org/licenses/by/ $4.0 /)$.

\begin{abstract}
The marine carotenoids fucoxanthin and siphonaxanthin are powerful antioxidants that are attracting focused attention to identify a variety of health benefits and industry applications. In this study, the binding energy of these carotenoids with the SARS-CoV-2 Spike-glycoprotein was predicted by molecular docking simulation, and their inhibitory activity was confirmed with SARS-CoV-2 pseudovirus on HEK293 cells overexpressing angiotensin-converting enzyme 2 (ACE2). Siphonaxanthin from Codium fragile showed significant antiviral activity with an IC50 of $87.4 \mu \mathrm{M}$ against SARS-CoV-2 pseudovirus entry, while fucoxanthin from Undaria pinnatifida sporophyll did not. The acute toxicities were predicted to be relatively low, and pharmacokinetic predictions indicate GI absorption. Although further studies are needed to elucidate the inhibition of viral infection by siphonaxanthin, these results provide useful information in the application of these marine carotenoids for the treatment and prevention of COVID-19.
\end{abstract}

Keywords: COVID-19; siphonaxanthin; fucoxanthin; carotenoid; seaweed; antiviral activity; molecular docking

\section{Introduction}

Since the first approval of a COVID-19 vaccine in December 2020, more than 1.04 billion doses have been administered in 172 countries [1-3], but COVID-19 is still spreading worldwide with multiple variants [4] and causing tremendous fear. According to Bloomberg, the latest vaccination rate is an average of $19,214,353$ doses per day worldwide, and they estimate that it will take another 18 months to cover $75 \%$ of the population with a two-dose vaccine at the current rate $[3,4]$. Although vaccination has begun worldwide, it will take a long time to safely achieve herd immunity against COVID-19 by vaccine, so effective therapies are still needed to prevent or treat COVID-19 [3].

Seaweeds are a rich source of carotenoids [5] such as fucoxanthin, lutein, $\beta$-carotene, and siphonaxanthin. Such carotenoids are powerful antioxidants that can protect the body from oxidative stress and have been extensively studied for the prevention of cardiovascular diseases, neurodegenerative diseases, and cancer [6,7]. One of the polar xanthophylls, fucoxanthin (FX), which is a characteristic orange, is abundant in several brown seaweeds including Undaria pinnatifida [8,9], Hijikia fusiformis [10], Laminaria japonica [11], Sargassum sp. [12-16], and Fucus sp. [17]. It is one of the most abundant carotenoids in seaweeds, accounting for more than $10 \%$ of the estimated total natural production of carotenoids [18]. Another polar xanthophyll, siphonaxanthin (SX), is a xanthophyll found in green algae such as Caulerpa lentillifera, Codium fragile, and Codium cylindricum [19]. As an oxidative metabolite of lutein, it possesses a structure similar to lutein except for one keto group located at C-8 and an extra hydroxyl group at C-19. These carotenoids have been shown to possess several potential bioactivities such as anticancer, anti-inflammatory, 
anti-obesity, and neuroprotective effects [20-22]. Naturally sourced carotenoids may be an underexplored source for novel antiviral treatments.

In this study, we investigated the inhibitory activity of two polar xanthophylls, fucoxanthin from Undaria pinnatifida sporophyll and siphonaxanthin from Codium fragile, against SARS-CoV-2 virus infection (using the SARS-CoV-2 pseudovirus) in HEK293/ ACE2 cells. This study aims to provide useful information for the application of marine carotenoids beneficial to human health.

\section{Results}

\subsection{Molecular Docking}

After visual inspection of the top-ranked poses, the potential binding sites were found for the FX and SX models: the region corresponding to the binding site of the SARS-CoV-2 chimeric receptor-binding domain (RBD) with ACE2 (Figure 1) [23]. The binding energies and residue interactions with the test compounds are presented in Table 1 . The binding energies of FX and SX for the RBD were $-2.91 \mathrm{kcal} / \mathrm{mol}$ and $-2.78 \mathrm{kcal} / \mathrm{mol}$, respectively. FX displayed a higher binding energy than SX, but it could not bind at the RBD-ACE2 binding site (Figure 1A,B). On the other hand, SX could bind at that location (Figure 1A,C), but its binding energy was slightly lower than FX. As shown in Figure 2, the potential interaction of RBD with ligands was hydrophobic in nature, and the interacting residues between RBD and SX were similar to those of ACE2 (Tyr449, Tyr 489, and Gln 493), while FX bound to the surface of RBD (Figure 2A).

\section{(A)}

(B)
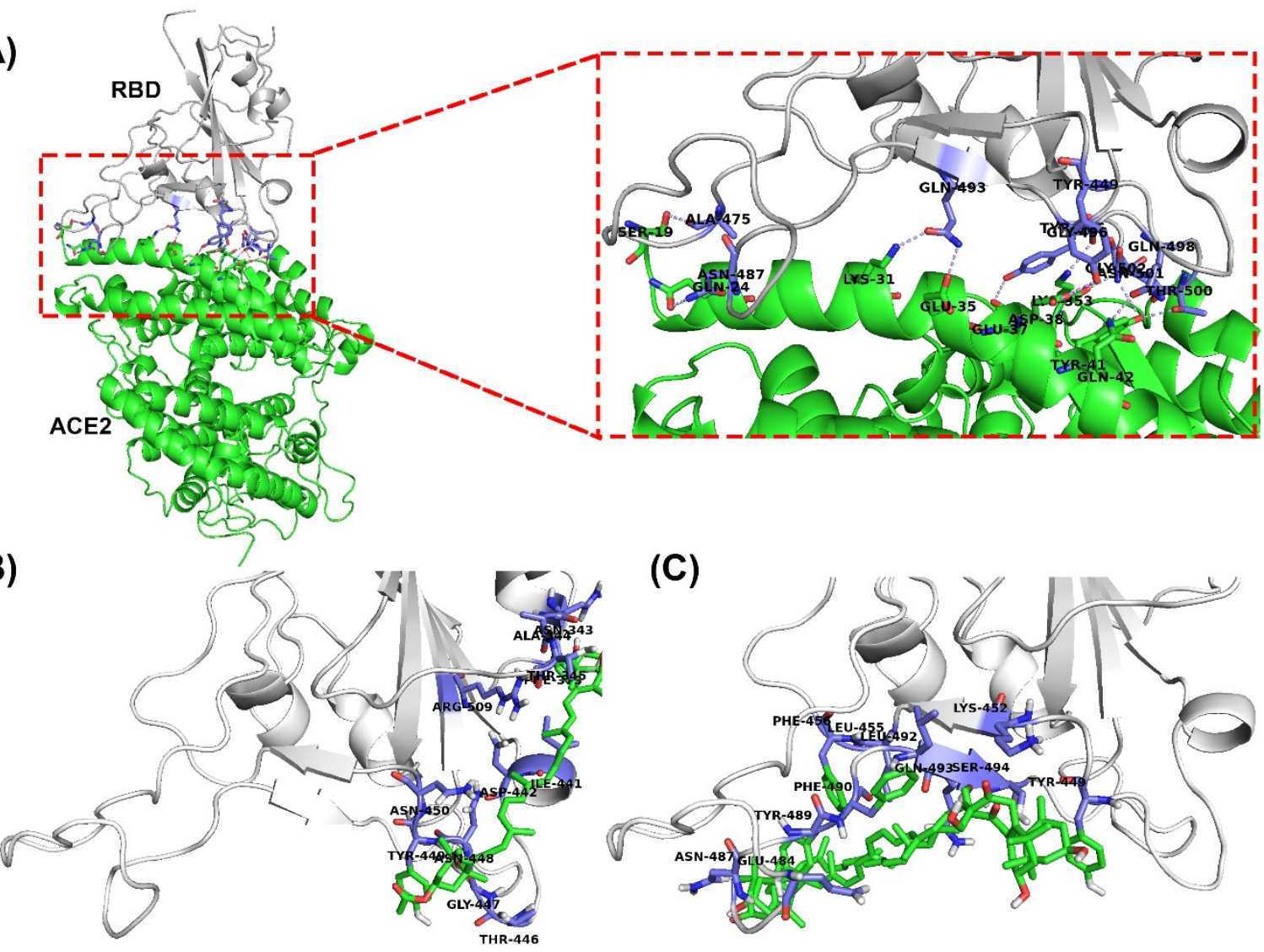

(C)

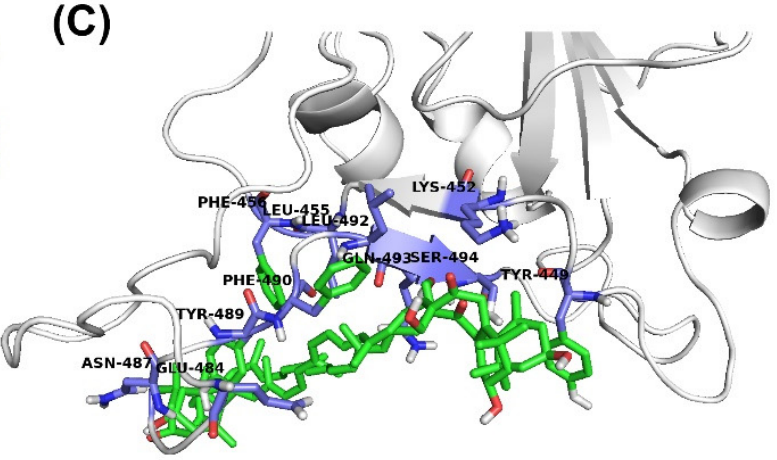

Figure 1. Surface and cartoon representations of structures of (A) the SARS-CoV-2 chimeric receptor-binding domain (RBD) complexed with angiotensin-converting enzyme 2 (ACE2). The molecular docking poses of (B) fucoxanthin and (C) siphonaxanthin interacting with RBD (PDB:6vw1) analyzed with AutoDock Vina. The tertiary structures of RBD-ligands were made with PyMOL. Ligands and ACE2 are depicted as green sticks and green cartoons, and the binding site residues are labeled accordingly. 
Table 1. Interaction and binding energy of ligands with SARS-CoV-2 chimeric receptor-binding domain (RBD) in silico.

\begin{tabular}{|c|c|c|}
\hline \multirow[b]{2}{*}{ Compounds } & \multicolumn{2}{|c|}{ SARS-CoV-2 Chimeric Receptor-Binding Domain (PDB:6VW1) } \\
\hline & $\begin{array}{l}\text { Binding Energy } \\
\left(\mathrm{kcal} \mathrm{mol}^{-1}\right)\end{array}$ & Interactions \\
\hline ACE2 & n.d. & $\begin{array}{l}\text { Tyr449, Ala475, Asn487, Tyr489, Gln493, Gly496, } \\
\text { Gln498, Thr500, Asn501, Gly502, Tyr505, }\end{array}$ \\
\hline Fucoxanthin & -2.91 & $\begin{array}{l}\text { Asn343, Ala344, Thr345, Phe373, Ile441, Asp442, } \\
\text { Thr446, Gly447, Asn448, Tyr449, Asn450, Arg509 }\end{array}$ \\
\hline Siphonaxanthin & -2.78 & $\begin{array}{l}\text { Tyr449, Lys452, Leu455, Phe456, Glu484, Asn487, } \\
\text { Tyr489, Phe490, Leu492, Gln493, Ser494 }\end{array}$ \\
\hline
\end{tabular}

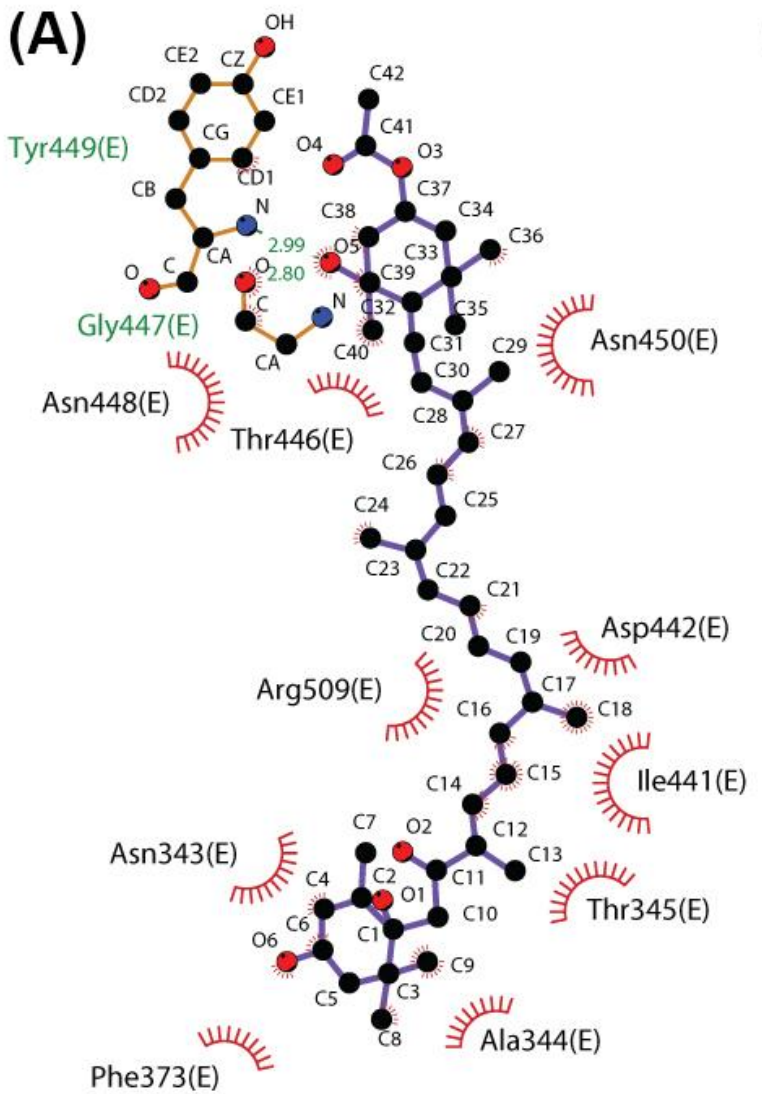

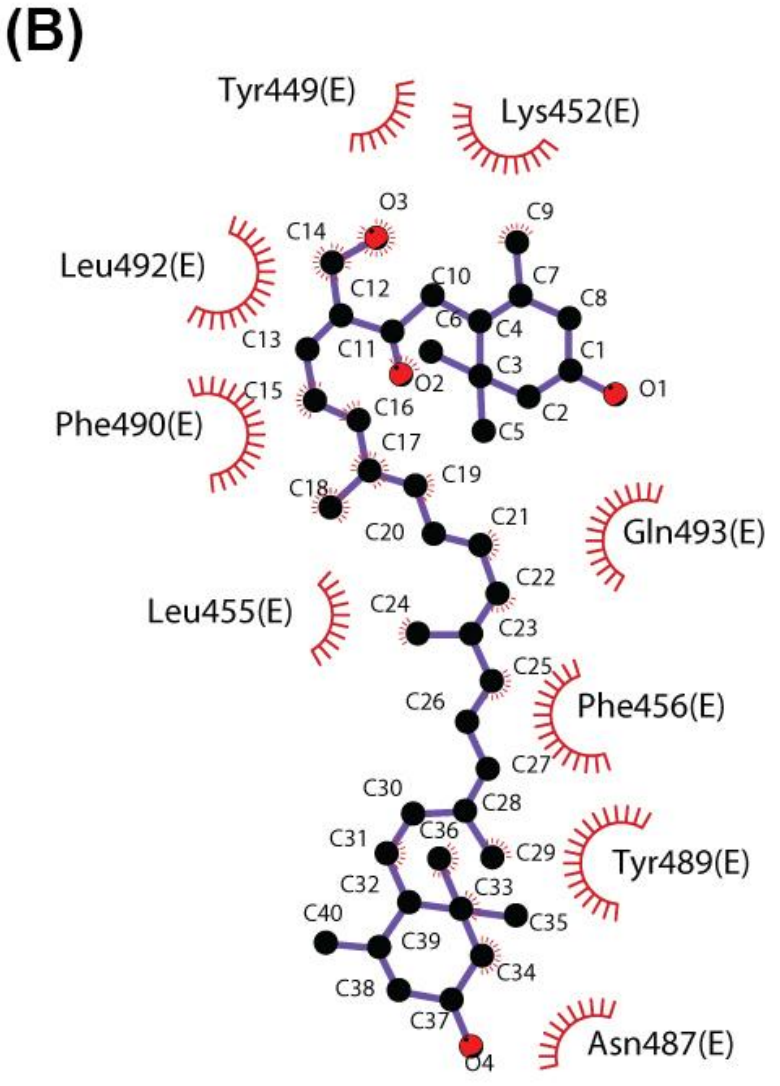

\section{(

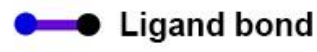 \\ Corresponding atoms involved in hydrophobic contact(S)

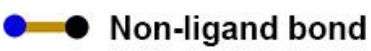 \\ -.... Hydrogen bond and its length}

Figure 2. The potential protein-ligand interactions of SARS-CoV-2 chimeric receptor-binding domain (RBD) and ligands. The best-docked poses for (A) fucoxanthin and (B) siphonaxanthin in RBD were made with LigPlot.

\subsection{Cytotoxicity Assay}

The viability of HEK293/ACE2 cells was assessed using a Cell Titer-Glo Luminescent cell viability assay kit (Promega, Madison, WI, USA). When the HEK293/ACE2 cells were treated with FX and SX at the final concentration range from $32 \mathrm{nM}$ to $100 \mu \mathrm{M}$ (serially diluted $1 / 5$ ) for $96 \mathrm{~h}$, the test compounds did not show cytotoxicity until $100 \mu \mathrm{M}$, when they showed minor cytotoxicity (Figure 3). 
(A)

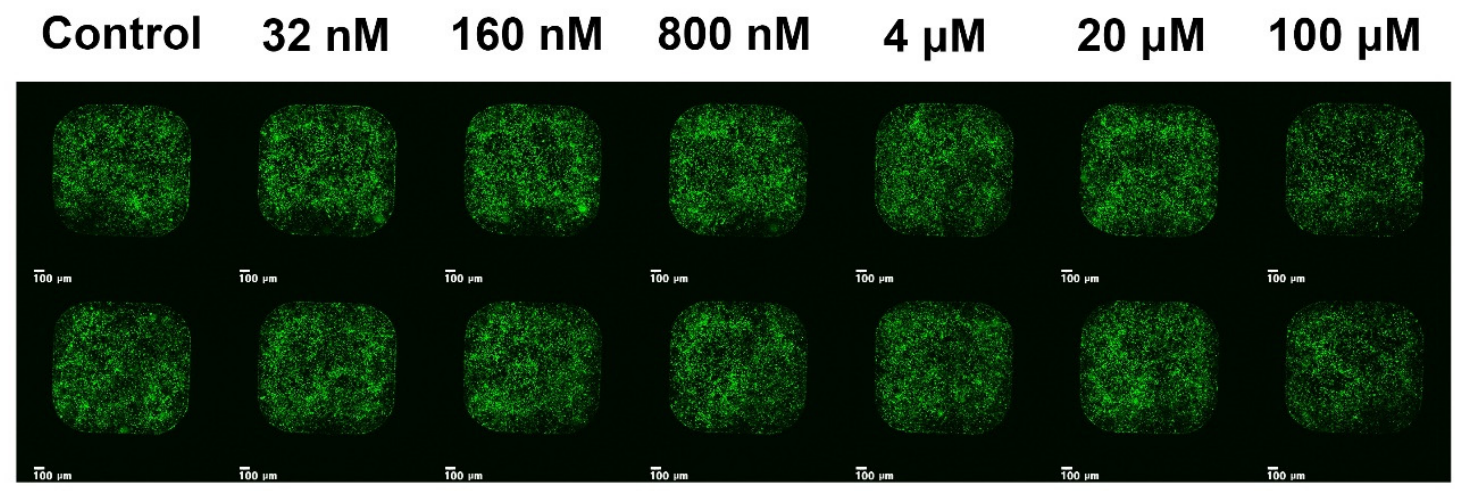

(B)

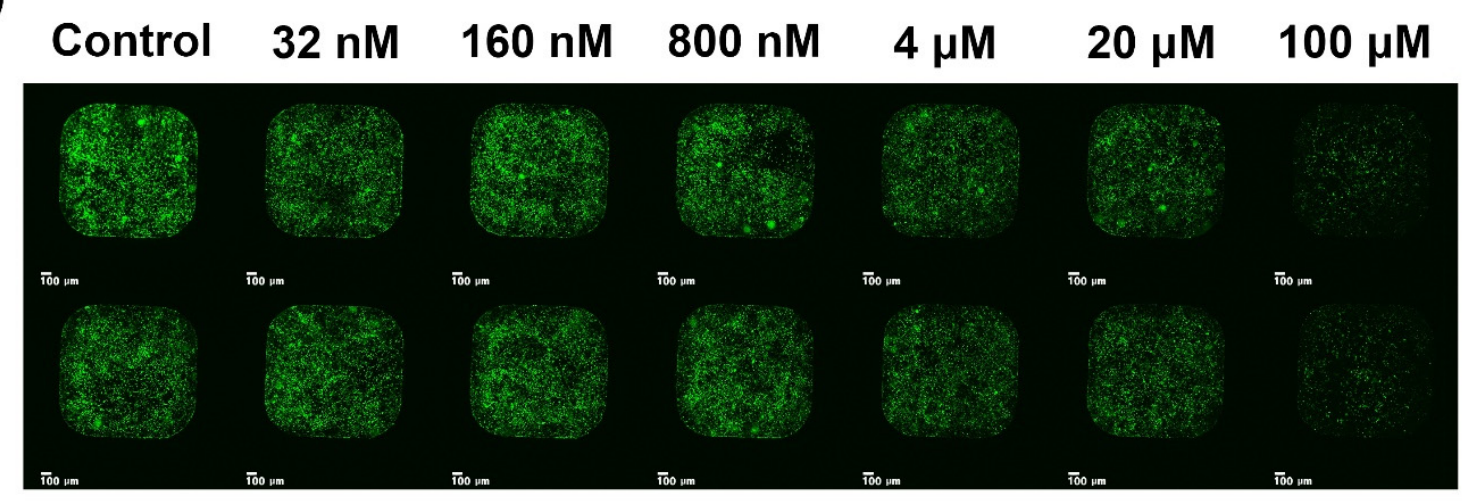

Figure 3. The GFP fluorescence, due to infection after treatment with pseudovirus and the indicated concentrations of (A) fucoxanthin and (B) siphonaxanthin for 96 h, in HEK293/ACE2 was scanned with an MBD ASFA scanner (MBD Biotech, Suwon, Korea). Green fluorescence indicates HEK293/ACE2 cells infected with pseudovirus. Scale bar: $100 \mu \mathrm{m}$.

\subsection{Inhibition of Viral Infection}

Inhibition of viral infection by FX and SX was performed with a SARS-CoV-2 pseudovirus. As shown in Figures 2 and 3, SX inhibited SARS-CoV-2 pseudovirus infection of HEK293/ACE2 cells at various concentrations. After exposure, the viral infection rate was visualized by GFP fluorescence imaging, which is presented in Figure 3. It was observed that viral infection mostly decreased with the increasing concentrations of SX. The SX showed antiviral activity with an IC50 of $87.4 \mu \mathrm{M}$, while FX displayed no antiviral activity against SARS-CoV-2 entry.

\subsection{Acute Toxicity and ADME Prediction}

General Unrestricted Structure-Activity Relationships (GUSAR) software [24] was used for quantitative in silico toxicity prediction for FX and SX in rats with four types of administration (oral, intravenous, intraperitoneal, and subcutaneous). As shown in Table 2, the difference in LD50 values obtained for the four different routes suggests that availability of the tested compound for metabolism by the liver is a major factor in its toxicity. The LD50 value of SX was higher than FX for intravenous (IV), oral, and subcutaneous (SC) routes of administration, but the LD50 value of FX was higher through intraperitoneal (IP) administration. By the OECD chemical classification system, FX and SX are Class 4 when administered through IP and oral routes, whereas they are Class 3 for IV and SC routes of administration. The ADME (absorption, distribution, metabolism, and elimination) properties of FX and SX were predicted by SwissADME [25] (Table 3). FX and SX had lipophilicities of 6.78 and $6.53(\log$ Po/w), respectively, and low GI adsorption. Moreover, their bioavailability scores and water solubilities were 0.17 and poorly soluble, respectively. 
Table 2. Prediction of acute toxicity in silico by GUSAR in rodent models and chemical classification of compounds.

\begin{tabular}{cccccc}
\hline Ligands & $\begin{array}{c}\text { Rat Oral LD50 } \\
(\mathbf{m g} / \mathbf{k g})\end{array}$ & $\begin{array}{c}\text { Rat IV LD50 } \\
\mathbf{( m g / k g )}\end{array}$ & $\begin{array}{c}\text { Rat SC LD50 } \\
\mathbf{( m g / k g )}\end{array}$ & $\begin{array}{c}\text { Rat IP LD50 } \\
\mathbf{( m g} / \mathbf{k g})\end{array}$ & $\begin{array}{c}\text { OECD Chemical } \\
\text { Classification }\end{array}$ \\
\hline Fucoxanthin & $1,752,000$ & 14,250 & 23,590 & 453,800 & Class 3 and 4 \\
Siphonaxanthin & $1,907,000$ & 17,070 & 52,120 & 434,400 & Class 3 and 4 \\
\hline
\end{tabular}

IP: Intraperitoneal; IV: Intravenous; LD50: Lethal dosage-50; OECD: Organisation for economic co-operation and development; SC: Subcutaneous.

Table 3. Pharmacokinetic parameters of compounds by SwissADME in silico.

\begin{tabular}{|c|c|c|c|c|c|c|c|}
\hline Ligands & $\underset{\text { (Lipophilicity) }}{\log \text { Po/w }}$ & $\underset{\text { Absorption }}{\text { GI }}$ & $\begin{array}{c}\text { BBB } \\
\text { Permeant }\end{array}$ & $\begin{array}{l}\text { CYP1A2 } \\
\text { Inhibitor }\end{array}$ & $\begin{array}{l}\text { Druglikeness } \\
\text { (Lipinski, } \\
\text { Violations) }\end{array}$ & $\begin{array}{l}\text { Bioavailability } \\
\text { Score }\end{array}$ & $\begin{array}{l}\text { Water Solubility } \\
\text { (LogS) }\end{array}$ \\
\hline Fucoxanthin & 6.78 & Low & No & No & $\begin{array}{c}\text { No; } \\
2 \text { violations }\end{array}$ & 0.17 & $\begin{array}{c}-8.20 \\
\text { (Poorly soluble) }\end{array}$ \\
\hline Siphonaxanthin & 6.53 & Low & No & No & $\begin{array}{c}\mathrm{No} ; \\
2 \text { violations }\end{array}$ & 0.17 & $\begin{array}{l}-8.00 \\
\text { (Poorly soluble) }\end{array}$ \\
\hline
\end{tabular}

BBB: Blood-brain barrier; CYP: Cytochrome P450; GI: Gastrointestinal tract.

\section{Discussion}

Two polar xanthophylls, FX from Undaria pinnatifida sporophyll and SX from Codium fragile, have been shown to possess several potential bioactivities including anticancer, anti-inflammatory, and anti-obesity effects, and serve as powerful antioxidants [20-22]. In this present study, whether these compounds can bind in the ACE2 binding region of the SARS-CoV-2 spike-protein was predicted using AutoDockTools and the inhibition of SARS-CoV-2 entry by these compounds was confirmed using a SARS-CoV-2 pseudovirus and HEK293/ACE2 in vitro.

In molecular docking, FX and SX displayed low binding energy $(-2.91$ and $-2.78 \mathrm{kcal} / \mathrm{mol}$, respectively), but SX fit exactly into the ACE2 binding region of RBD (Figure 1C), unlike FX (Figure 1B). The reason seems to be that FX is more hydrophobic than SX. Fucoxanthin has an epoxide and an allenic bond in its structure, whereas siphonaxanthin does not contain either of those functional groups. However, it possesses an additional hydroxyl group on the 19th carbon atom [26]. In SwissADME results, the lipophilicity of FX is higher (6.78) than SX (6.53), and the water solubility of FX is lower (-8.2) than SX $(-8.0)$ in silico (Table 3). These results support the conclusion that SX is more hydrophilic than FX and could more easily bind to the binding site of S-glycoprotein for ACE2. As in Unni et al. [27], the binding site was divided into three hydrophilic regions based on the electrostatic character of the surface in each region of the S-glycoprotein-ACE2 interface, referred to as Site1 (Gly446, Tyr449, Gly496, Gln498, Thr500, and Asn501), Site 2 (Lys417 and Gln493), and Site 3 (Ala475 and Asn487) on the S-glycoprotein. The interaction of SX and S-protein spanned Site 1 (Tyr449), Site2 (Gln493), and Site 3 (Asn487), but FX only made contact with Site 1 (Thr446 and Tyr449).

In vitro, the antiviral activities of SX and FX against SARS-CoV-2 fit our expectations from the molecular docking simulations. FX displayed no antiviral activity (Figure 4A), while SX showed antiviral activity with an IC50 of $87.4 \mu \mathrm{M}$ (Figure 4C) against SARS-CoV-2 entry. These results indicate that SX effectively interferes with interaction of S-glycoprotein and ACE2, but FX does not. In recent studies, sulfated polysaccharides [28,29], fucoidan [30], and some crude polysaccharide extractions [31] effectively inhibited SARS-CoV-2 entry in vitro. According to studies so far, highly branched and sulfated polysaccharides with high molecular weight can effectively inhibit COVID-19 viral infection. Although carotenoids are known to have beneficial effects on health and diverse applications [32], such as antibacterial, antiviral, antifungal, anticancer, antidiabetic, anti-inflammatory, antioxidant, anti-obesity, and neuroprotective applications, there are no studies related to how marine carotenoids can inhibit SARS-CoV-2 entry. These results show for the first time that SX, a marine carotenoid rather than polysaccharide, significantly inhibits SARS-CoV-2 viral infection without cytotoxicity at a dose of less than $100 \mu \mathrm{M}$. 
(A)

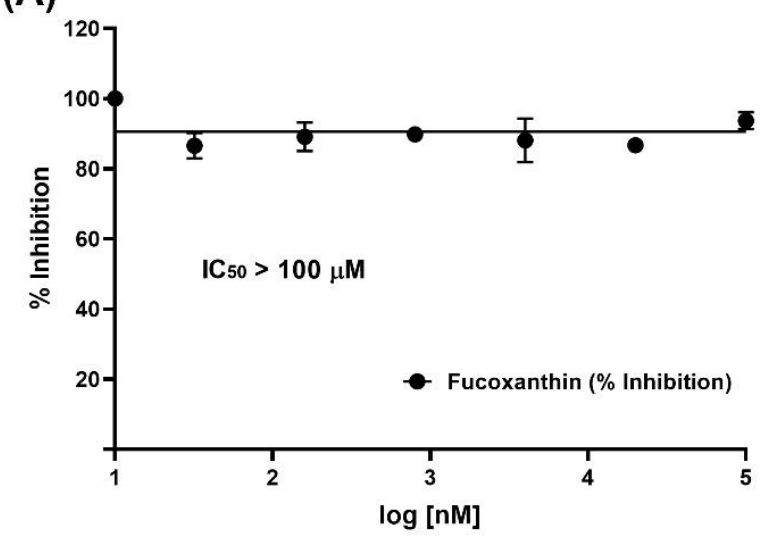

(C)

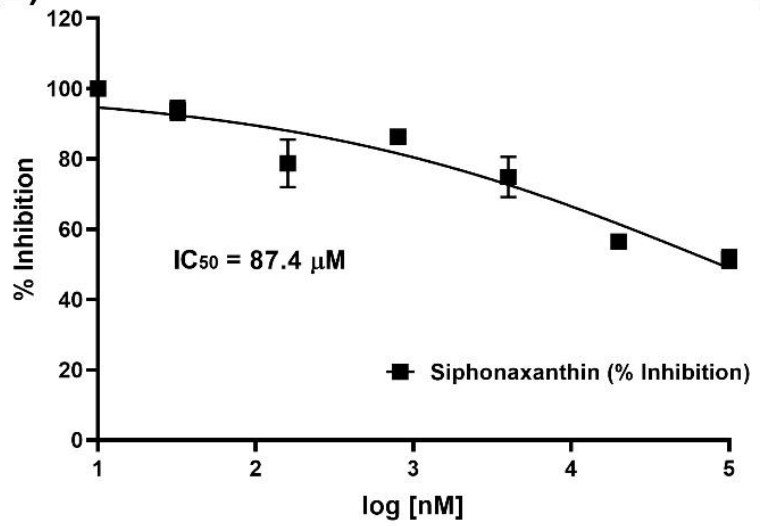

(B)

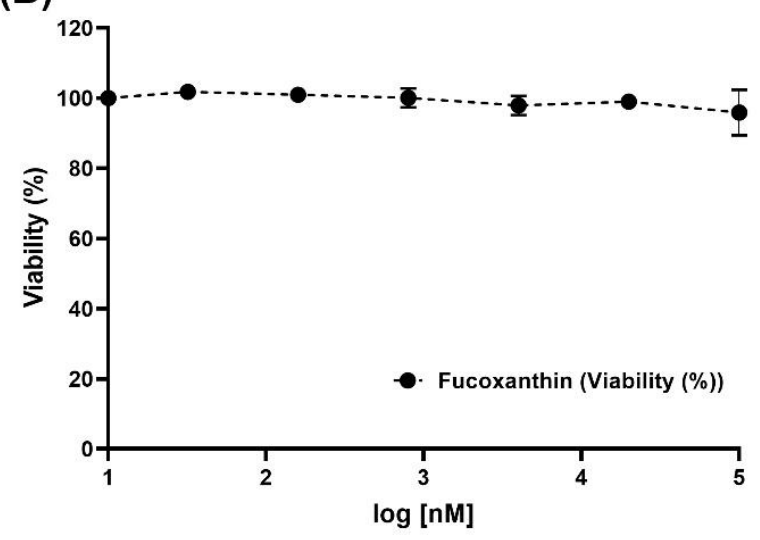

(D)

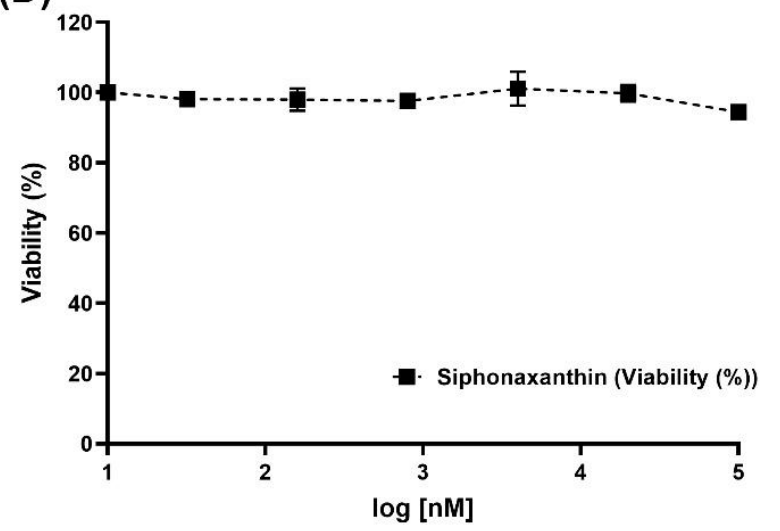

Figure 4. Determination of the cytotoxicity and antiviral activity of the fucoxanthin and siphonaxanthin in HEK293/ACE2 cells. The inhibition of viral infection by the (A) fucoxanthin and (C) siphonaxanthin was performed with SARS-CoV-2 pseudovirus containing the S-glycoprotein of SARS-CoV-2 (COVID-19). The viability of HEK293/ACE2 cells was assessed using an CellTiter-Glo ${ }^{\circledR}$ Luminescent cell viability assay kit (Promega, Madison, WI, USA) after treatment with the indicated concentrations of the (B) fucoxanthin and (D) siphonaxanthin for $96 \mathrm{~h}$. Results are expressed as percent of inhibition in drug-treated cultures compared with untreated and was plotted with GraphPad Prism software (Graph-Pad, San Diego, CA, USA). Values are the means \pm S.D. $(n=3)$.

Determining the acute toxicity and pharmacokinetic properties of these marine carotenoids was facilitated by GUSAR software [24] and SwissADME [25]. The toxicity profile of these compounds is relatively low, and they require high doses to elicit toxic responses. As shown in Table 2, FX and SX are Class 4 chemicals that have mild toxic effects when administered orally or intraperitoneally, but they are Class 3 intravenously and subcutaneously. Commercially, FX and SX are sold as health supplements because these compounds are believed to possess a variety of health benefits [20-22]. However, in previous studies, FX inhibited the activity of CYP1A2 and CYP3A4 with an IC50 of $30.3 \mu \mathrm{M}$ and $24.4 \mu \mathrm{M}$, respectively [33-35]. These CYPs are responsible for the metabolism of more than $60 \%$ of commonly prescribed drugs [36]. The inhibition by FX against CYPs may reduce the effects of drugs that are administered as a pro-drug which needs to be broken down into its active form, and it may also enhance the cytotoxicity of drugs by causing them to linger in the body longer, and at higher levels than expected. SX did not show the inhibition of CYP1A2 and CYP3A4 activities in vitro, but little information on its in vitro cytotoxicity and in vivo bioavailability and biotransformation is available. Recently, $\mathrm{Li}$ et al. [37] reported that SX mainly accumulates in the stomach and small intestine but was detected in the plasma and most tissues (except the bladder) of mice at the end of a 16-day dietary supplementation with SX $(0.004 \%)$, while putative metabolites of SX mainly accumulated in liver and adipose tissues. These observations suggest that $S X$ can 
be absorbed and metabolized in mice, but the ultimate destiny of SX in the human body requires further study.

In summary, SX inhibits SARS-CoV-2 virus infection even in vitro, as predicted by molecular docking in silico. Additionally, SX has been shown to possess several potential bioactivities including anticancer, anti-inflammatory, and anti-obesity effects, and it is a powerful antioxidant. Although further studies are needed to elucidate the inhibition mechanisms of SX against SARS-CoV-2 virus infection and identify the biological activities of SX in vitro and vivo when SARS-CoV-2 virus is present, this study provides useful information for application of these beneficial marine carotenoids in improving human health.

\section{Materials and Methods}

\subsection{Chemicals and Reagents}

All analytical grade organic solvents including hexane, chloroform, acetonitrile, and methanol were purchased from Burdick \& Jackson chemicals (Muskegon, MI, USA). Ultrapure argon (99.99\%), nitrogen (99.99\%), and carbon dioxide were supplied from Daechang Gas (Songha-dong, Gwangju, South Korea). Fucoxanthin (FX) and siphonaxanthin (SX) were extracted and purified from sporophyll of Undaria pinnatifida and Codium fragile, respectively, for a previous study [35].

\subsection{Docking Studies}

Chemical structures of FX (Compound CID:5281239) and SX (Compound CID:11204185) were obtained from PubChem database (https:/ / pubchem.ncbi.nlm.nih.gov). Test compounds in sdf format were formatted to pdbqt files with OpenBabel [38]. The threedimensional structures for SARS-CoV-2 chimeric RBD (PDB: 6VW1, chain C) [23] was downloaded from the Protein Data Bank (https://www.rcsb.org) [39]. The removal of counter-ions, crystallographic waters, and other ligands (except the heme group) and the addition of atomic charges and solvation parameters were done using AutoDockTools (version 1.5.6) [40]. The ligand ACE2 (angiotensin-converting enzyme 2, PDB: 6VW1, chain A) was used as the control for the SARS-CoV-2 spike-glycoprotein. Docking calculations were carried out using AutoDock Vina (version 1.1.2) [41]. Grids were centered on coordinates $63.141,-13.492$, and 185.392 with $1.0 \AA$ grid spacing and dimensions of $60 \AA \times 60 \AA \times 60 \AA$ on $x$-, $y$-, and $z$-axes for the RBD. The top-ranked binding modes and protein-ligand interactions were visualized with PyMOL Molecular Graphics system (Shrödinger, LLC, version 1.8), Protein-ligand Interaction Profiler [42], and LigPlot [43].

\subsection{SARS-CoV-2 Pseudovirus and Cell}

SARS-CoV-2 Pseudovirus (COV-PS02) expressing S-glycoprotein on the surface of the Lentivirus and HEK293/ACE2 cell genetically engineered to overexpress angiotensinconverting enzyme 2 were purchased from Creative Diagnostics (Shirley, NY, USA). Dulbecco's modified Eagle's medium (DMEM), fetal bovine serum (FBS), and geneticin (G-418 sulfate) were purchased from Thermo Fisher Scientific (Waltham, MA, USA), and the Cell Titer-Glo Luminescent cell viability assay kit was purchased from Promega (Madison, WI, USA). HEK293/ACE2 was maintained at $37^{\circ} \mathrm{C}, 5 \% \mathrm{CO}_{2}$ in Dulbecco's modified Eagle medium (DMEM) supplemented with $10 \%(v / v)$ heat-inactivated fetal bovine serum and $0.5 \mathrm{mg} \mathrm{mL}^{-1}$ of G418. The cells were sub-cultured within $48 \mathrm{~h}$ intervals.

\subsection{Cytotoxicity Assay}

The cytotoxicity evaluation of FX and SX was performed using a Cell Titer-Glo Luminescent cell viability assay kit. After the HEK293/ACE2 cells were each treated with $20 \mu \mathrm{L}$ of FX or SX at various concentrations (5-fold serial dilutions in the range of $32 \mathrm{nM}$ to $100 \mu \mathrm{M}$, final DMSO 1\%) for $96 \mathrm{~h}, 4 \mu \mathrm{L} /$ well of Cell titer Glo reagent was added, and the 
plate was shaken for $2 \mathrm{~min}$ at $700 \mathrm{rpm}$. After $10 \mathrm{~min}$, the mixture was read via luminometer and cell viability was calculated as follows:

$$
\text { Cell Viability }(\%)=\frac{R L U \text { sample }}{\text { RLU conc. }} \times 100
$$

where the RLU sample is the luminescence of the experimental sample, and RLU conc. is the luminescence of the control. Cytotoxicity was calculated as follows:

$$
\text { Cytotoxicity }(\%)=100-\% \text { Cell Viability }
$$

The 50\% cytotoxic concentration for FX and SX was determined using nonlinear regression analysis with GraphPad Prism software (Graph-Pad, San Diego, CA, USA). Each sample was analyzed in duplicate wells and repeated three times.

\subsection{Inhibition of Viral Infection}

To investigate the inhibitory effects of FX and SX on viral infection, HEK293/ACE2 was seeded in 384-well plates at a concentration of $2 \times 10^{3}$ cells/well using DMEM and incubated at $37^{\circ} \mathrm{C}, 5 \% \mathrm{CO}_{2}$ for $24 \mathrm{~h}$. When the HEK293/ACE2 cells had grown to a density of 30-40\% in a 384-well plate, the cells were treated with the mixture of each $20 \mu \mathrm{L}$ of FX or SX (serial diluted $1 / 5$ in a concentration range of $32 \mathrm{nM}$ to $100 \mu \mathrm{M}$, final DMSO $1 \%$ ) and $1 \mu \mathrm{L}$ of SARS-CoV-2 pseudovirus (titer: $1.0 \times 10^{7} \mathrm{TU} \mathrm{mL}^{-1}$ ) to induce viral infection. After $96 \mathrm{~h}$ incubation, the viral infection rate was analyzed by scanning for GFP fluorescence with an MBD ASFA scanner (MBD Biotech., Suwon, South Korea). To calculate the inhibition of cell penetration by the SARS-CoV-2 pseudovirus, the GFP fluorescence area of infected cells was analyzed with an MBD cell analyzer and was calculated as follows:

$$
\% \text { inhibition }=\frac{(\text { GFP AREA sample })}{(\text { GFP AREA conc. })} \times 100
$$

where the GFP AREA sample is the GFP area $\left(\mu \mathrm{m}^{2}\right)$ of the experimental sample and GFP AREA conc. is the GFP area $\left(\mu \mathrm{m}^{2}\right)$ of the control. Antiviral activity was calculated as follows:

$$
\text { Antiviral activity }(\%)=100-\% \text { inhibition }
$$

Each sample was analyzed in triplicate, and the plots were made with GraphPad Prism software (Graph-Pad, San Diego, CA, USA).

\subsection{ADMET Prediction}

FX and SX were investigated for ADMET (adsorption, distribution, metabolism, excretion, and toxicity) properties in silico. The acute toxicity in rodent models and chemical classification of the test compounds were predicted by GUSAR [24]. It analyzes compounds based on the Quantitative Neighborhoods of Atoms descriptors and Prediction of Activity Spectra for Substances algorithm and correlates the obtained results with the SYMYX MDL toxicity Database and further classifies them based on the Organisation for Economic Co-operation and Development (OECD) chemical classification manual. The pharmacokinetics parameters were predicted by SwissADME [25] to ascertain the behavior of these compounds inside an organism in terms of absorption, distribution, metabolism, and excretion.

\subsection{Statistical Analysis}

The area of fluorescent cells infected by the pseudovirus was measured using the MBD Cell Analyzer. All experiments were performed in duplicate wells and repeated three times. The half maximal inhibitory concentrations $\left(\mathrm{IC}_{50}\right)$ were calculated in $\mathrm{GraphPad}$ 
Prism 9 software using nonlinear regression analysis with log (inhibitor) plotted against the normalized response (variable slope). The equation corresponds to:

$$
Y=100 /\left(1+10^{\wedge}((\log \text { IC50 }-X) \times \text { Hillslope })\right)
$$

where $Y$ is the response, $X$ is the logarithm of doses or concentrations, and Hillslope describes the steepness of the family of curves.

Author Contributions: S.-K.Y., B.K., K.J. and J.K. conceived and designed the experiments; S.-K.Y., B.W. and I.K. performed the experiments; S.-K.Y., B.W. and I.K. prepared reagents and materials; S.-K.Y. and B.W. performed docking analysis; J.K., B.K. and S.-K.Y. analyzed the data; S.-K.Y. wrote the manuscript. All authors have read and agreed to the published version of the manuscript.

Funding: This research was funded by the Jeonnam Provincial Government and Wando County through the research support grant project for screening the antiviral activity of seaweeds against COVID-19 during the period 2020-2021.

Institutional Review Board Statement: Not applicable.

Informed Consent Statement: Not applicable.

Data Availability Statement: The data presented in this study are available on request from the corresponding author.

Acknowledgments: The authors thank the Jeonnam Provincial Government and Wando County, Korea for their help and thank Seok-Joon Kwon (Rensselaer Polytechnic Institute, Troy, NY, USA) and Jung Joo Hong (Korea Research Institute of Bioscience and Biotechnology, Cheongju, Chungcheongbukdo, Korea) for giving advice on antiviral study.

Conflicts of Interest: The authors declare that they have no conflict of interest.

\section{Abbreviations}

FX: fucoxanthin; SX: siphonaxanthin; COV-PS02: SARS-CoV-2 pseudovirus; RBD: SARS-CoV-2 chimeric receptor-binding domain; ACE2: angiotensin-converting enzyme 2; GUSAR: General Unrestricted Structure-Activity Relationships; ADMET: absorption, distribution, metabolism, elimination, and toxicity.

\section{References}

1. U.S. Food and Drug Administration. COVID-19 Vaccines. Available online: https://www.fda.gov/emergency-preparednessand-response/coronavirus-disease-2019-covid-19/covid-19-vaccines\#news (accessed on 27 April 2021).

2. COVID-19 Vaccine Tracker. Available online: https://www.bloomberg.com/graphics/covid-vaccine-tracker-global-distribution (accessed on 27 April 2021).

3. Coronavirus (COVID-19) Vaccinations Tracker. Available online: https:/ / ourworldindata.org/covid-vaccinations (accessed on 27 April 2021).

4. Variants of SARS-CoV-2. Available online: https://en.wikipedia.org/wiki/Variants_of_SARS-CoV-2 (accessed on 27 April 2021).

5. Boominathan, M.; Mahesh, A. Seaweed carotenoids for cancer therapeutics. In Handbook of Anticancer Drugs from Marine Origin; Kim, S.-K., Ed.; Springer: Cham, Switzerland, 2015; pp. 185-203.

6. Brown, E.S.; Allsopp, P.J.; Magee, P.J.; Gill, C.I.R.; Nitecki, S.; Strain, C.R.; McSorley, E.M. Seaweed and human health. Nutr. Rev. 2014, 72, 205-216. [CrossRef]

7. MacArtain, P.; Gill, C.I.R.; Brooks, M.; Campbell, R.; Rowland, I.R. Nutritional value of edible seaweeds. Nutr. Rev. 2007, 65, 535-543. [CrossRef] [PubMed]

8. Roh, M.K.; Uddin, M.S.; Chun, B.S. Extraction of fucoxanthin and polyphenol from Undaria pinnatifida using supercritical carbon dioxide with co-solvent. Biotechnol. Bioprocess Eng. 2008, 13, 724-729. [CrossRef]

9. Quitain, A.T.; Kai, T.; Sasaki, M.; Goto, M. Supercritical carbon dioxide extraction of fucoxanthin from Undaria pinnatifida. J. Agric. Food Chem. 2013, 61, 5792-5797. [CrossRef]

10. Yan, X.; Chuda, Y.; Suzuki, M.; Nagata, T. Fucoxanthin as the major antioxidant in Hijikia fusiformis, a common edible seaweed. Biosci. Biotechnol. Biochem. 1999, 63, 605-607. [CrossRef]

11. Wang, W.-J.; Wang, G.-C.; Zhang, M.; Tseng, C.K. Isolation of fucoxanthin from the rhizoid of Laminaria japonica Aresch. J. Integr. Plant Biol. 2005, 47, 1009-1015. [CrossRef] 
12. Heo, S.-J.; Jeon, Y.-J. Protective effect of fucoxanthin isolated from Sargassum siliquastrum on UV-B induced cell damage. J. Photochem. Photobiol. B 2009, 95, 101-107. [CrossRef]

13. Noviendri, D.; Jaswir, I.; Salleh, H.M.; Taher, M.; Miyashita, K.; Ramli, N. Fucoxanthin extraction and fatty acid analysis of Sargassum binderi and S. duplicatum. J. Med. Plants Res. 2011, 5, 2405-2412.

14. Conde, E.; Moure, A.; Domínguez, H. Supercritical $\mathrm{CO}_{2}$ extraction of fatty acids, phenolics and fucoxanthin from freeze-dried Sargassum muticum. J. Appl. Phycol. 2014, 2, 957-964. [CrossRef]

15. Nomura, M.; Kamogawa, H.; Susanto, E.; Kawagoe, C.; Yasui, H.; Saga, N.; Hosokawa, M.; Miyashita, K. Seasonal variations of total lipids, fatty acid composition, and fucoxanthin contents of Sargassum horneri (Turner) and Cystoseira hakodatensis (Yendo) from the northern seashore of Japan. J. Appl. Phycol. 2013, 25, 1159-1169. [CrossRef]

16. Afolayan, A.F.; Bolton, J.J.; Lategan, C.A.; Smith, P.J.; Beukes, D.R. Fucoxanthin, tetraprenylated toluquinone and toluhydroquinone metabolites from Sargassum heterophyllum inhibit the in vitro growth of the malaria parasite Plasmodium falciparum. Z. Naturforschung C J. Biosci. 2008, 63, 848-852. [CrossRef]

17. Zaragozá, M.C.; López, D.; Sáiz, P.M.; Poquet, M.; Pérez, J.; Puig-Parellada, P.; Màrmol, F.; Simonetti, P.; Gardana, C.; Lerat, Y.; et al. Toxicity and antioxidant activity in vitro and in vivo of two Fucus vesiculosus extracts. J. Agric. Food Chem. 2008, 56, 7773-7780. [CrossRef]

18. Peng, J.; Yuan, J.-P.; Wu, C.-F.; Wang, J.-H. Fucoxanthin, a marine carotenoid present in brown seaweeds and diatoms: Metabolism and bioactivities relevant to human health. Mar. Drugs 2011, 9, 1806-1828. [CrossRef]

19. Takaichi, S. Carotenoids in algae: Distributions, biosyntheses and functions. Mar. Drugs 2011, 9, 1101-1118. [CrossRef] [PubMed]

20. Kim, S.-K.; Pangestuti, R. Biological activities and potential health benefits of fucoxanthin derived from marine brown algae. Adv. Food Nutr. Res. 2011, 64, 111-128. [PubMed]

21. Gammone, M.A.; D'Orazio, N. Anti-obesity activity of the marine carotenoid fucoxanthin. Mar. Drugs 2015, 13, 2196-2214 [CrossRef] [PubMed]

22. Pangestuti, R.; Kim, S.-K. Carotenoids, bioactive metabolites derived from seaweeds. In Springer Handbook of Marine Biotechnology; Kim, S.-K., Ed.; Springer: Berlin/Heidelberg, Germany, 2015; pp. 816-821.

23. Shang, J.; Ye, G.; Shi, K.; Wan, Y.; Luo, C.; Aihara, H.; Geng, Q.; Auerbach, A.; Li, F. Structural basis of receptor recognition by SARS-CoV-2. Nature 2020, 581, 221-224. [CrossRef] [PubMed]

24. Lagunin, A.; Zakharov, A.; Filimonov, D.; Poroikov, V. QSAR modeling of rat acute toxicity on the basis of PASS prediction. Mol. Inform. 2011, 30, 241-250. [CrossRef] [PubMed]

25. Daina, A.; Michielin, O.; Zoete, V. SwissADME: A free web tool to evaluate pharmacokinetics, drug-likeness and medicinal chemistry friendliness of small molecules. Sci. Rep. 2017, 7, 42717. [CrossRef] [PubMed]

26. Sugawara, T.; Ganesan, P.; Li, Z.; Manabe, Y.; Hirata, T. Siphonaxanthin, a green algal carotenoid, as a novel functional compound. Mar. Drugs 2014, 12, 3660-3668. [CrossRef]

27. Unni, S.; Aouti, S.; Thiyagarajan, S.; Padmanabhan, B. Identification of a repurposed drug as an inhibitor of Spike protein of human coronavirus SARS-CoV-2 by computational methods. J. Biosci. 2020, 45, 130. [CrossRef] [PubMed]

28. Kwon, P.S.; Oh, H.; Kwon, S.-J.; Jin, W.; Zhang, F.; Fraser, K.; Hong, J.J.; Linhardt, R.J.; Dordick, J.S. Sulfated polysaccharides effectively inhibit SARS-CoV-2 in vitro. Cell Discov. 2020, 6, 50. [CrossRef] [PubMed]

29. Song, S.; Peng, H.; Wang, Q.; Liu, Z.; Dong, X.; Wen, C.; Ai, C.; Zhang, Y.; Wang, Z.; Zhu, B. Inhibitory activities of marine sulfated polysaccharides against SARS-CoV-2. Food Funct. 2020, 11, 7415-7420. [CrossRef] [PubMed]

30. Fitton, J.H.; Park, A.Y.; Karpiniec, S.S.; Stringer, D.N. Fucoidan and lung function: Value in viral infection. Mar. Drugs 2021, 19, 4. [CrossRef] [PubMed]

31. Yim, S.; Kim, K.; Kim, I.; Chun, S.; Oh, T.; Kim, J.; Kim, J.; Jung, W.; Moon, H.; Ku, B.; et al. Inhibition of SARS-CoV-2 virus entry by the crude polysaccharides of seaweeds and abalone viscera in vitro. Mar. Drugs 2021, 19, 219. [CrossRef] [PubMed]

32. Alam, M.A.; Parra-Saldivar, R.; Bilal, M.; Afroze, C.A.; Ahmed, M.N.; Iqbal, H.M.N.; Xu, J. Algae-derived bioactive molecules for the potential treatment of SARS-CoV-2. Molecules 2021, 26, 2134. [CrossRef]

33. Satomi, Y.; Nishino, H. Inhibition of the enzyme activity of cytochrome P450 1A1, 1A2 and 3A4 by fucoxanthin, a marine carotenoid. Oncol. Lett. 2013, 6, 860-864. [CrossRef] [PubMed]

34. Liu, C.-L.; Lim, Y.-P.; Hu, M.-L. Fucoxanthin attenuates rifampin-induced cytochrome P450 3A4 (CYP3A4) and multiple drug resistance 1 (MDR1) gene expression through pregnane $X$ receptor (PXR)-mediated pathways in human hepatoma HepG2 and colon adenocarcinoma LS174T cells. Mar. Drugs 2012, 10, 242-257. [CrossRef] [PubMed]

35. Yim, S.-K.; Kim, K.; Chun, S.-H.; Oh, T.; Jung, W.; Jung, K.; Yun, C.-H. Screening of human CYP1A2 and CYP3A4 inhibitors form seaweed in silico and in vitro. Mar. Drugs 2020, 18, 603. [CrossRef]

36. Shimada, T.; Yamazaki, H.; Mimura, M.; Inui, Y.; Guengerich, F.P. Interindividual variantions in human liver cytochrome P-450 enzymes involved in the oxidation of drugs, carcinogens and toxic chemicals: Studies with liver microsomes of 30 Japanese and 30 Caucasians. J. Pharmacol. Exp. 1994, 270, 414-423.

37. Li, Z.; Zheng, J.; Luo, X.; Manabe, Y.; Hirata, T.; Sugawara, T. Absorption and tissue distribution of siphonaxanthin from Green Algae. Mar. Drugs 2020, 18, 291. [CrossRef]

38. O’Boyle, N.M.; Banck, M.; James, C.A.; Morley, C.; Vandermeersch, T.; Hutchison, G.R. Open babel: An open chemical toolbox. J. Cheminform. 2011, 3, 1-14. [CrossRef] 
39. Berman, H.M.; Westbrook, J.; Feng, Z.; Gilliland, G.; Bhat, T.N.; Weissig, H.; Shindyalov, I.N.; Bourne, P.E. The protein data bank. Nucleic Acids Res. 2000, 28, 235-242. [CrossRef]

40. Morris, G.M.; Huey, R.; Lindstrom, W.; Sanner, M.F.; Belew, R.K.; Goodsell, D.S.; Olson, A.J. AutoDock4 and AutoDockTools4: Automated docking with selective receptor flexibility. J. Comput. Chem. 2009, 30, 2785-2791. [CrossRef] [PubMed]

41. Trott, O.; Olson, A.J. AutoDock Vina: Improving the speed and accuracy of docking with a new scoring function, efficient optimization and multithreading. J. Comput. Chem. 2010, 31, 455-461. [CrossRef] [PubMed]

42. Salentin, S.; Schreiber, S.; Haupt, V.J.; Adasme, M.F.; Schroeder, M. PLIP: Fully automated protein-ligand interaction profiler. Nucleic Acids Res. 2015, 1, W443-W447. [CrossRef] [PubMed]

43. Wallace, A.C.; Laskowski, R.A.; Thornton, J.M. LIGPLOT: A program to generate schematic diagrams of protein-ligand interactions. Protein Eng. 1995, 8, 127-134. [CrossRef] 